\title{
Examining Inter-disciplinary Commonalities in the Referents of I, We and You in Classroom Lecturer Talk
}

\author{
Osei Yaw Akoto1 (iD , Benjamin Amoakohene 2 (iD) \& Juliet Oppong- Asare Ansah ${ }^{3}$ (D) \\ 1 Department of English, Faculty of Social Sciences, College of Humanities and Social Sciences, Kwame Nkrumah University of Science and \\ Technology, Ghana. \\ 2 Department of General and Liberal Studies of the University of Health and Allied Sciences \\ 3 Department of Language and Communication Sciences, Faculty of Social Sciences, College of Humanities and Social Sciences, Kwame Nkrumah \\ University of Science and Technology, Ghana.
}

\begin{abstract}
Studies have sought to establish the 'territory of reference' or 'patterns of referentialities' of $I$, we and you (tri-PP) in academic lectures across disciplinary supercommunities (DSs): Humanities, Social Sciences and Natural Sciences. These studies are largely from L1 context, and also report on only referents common to the three DSs, without giving attention to those at the interface of two DSs. This study, therefore, is the first attempt to examine the referents of the tri-PP at the interface of two DSs in academic lectures, using a corpus from the L2 context. A corpus of over one hundred thousand words was built for the study, and AntConc was used to search for the occurrences of the tri-PP. Drawing on the contexts and co-texts, the authors determined the referents of the tri-PP. It was found that across the tri-PP, some referents were shared by two DSs. The findings further deepen understanding of the 'pointing' role of personal pronouns in classroom lecturer talk and "degree of cross-disciplinary diversity..."
\end{abstract}

Keywords: academic lectures, discourse referent, disciplinary variation, personal pronouns

\section{INTRODUCTION}

Over the years, studies on the variation in the discourse referents of $I$, we and you (the triumvirate personal pronouns -tri-PP) across disciplinary supercommunities (DSs) -Humanities, Social Sciences and Natural Sciences have adopted a macroscopic approach which arguably focused on the 'major' referents. ${ }^{1}$ This approach lumps up both metadiscursive and non-metadiscursive personal pronouns, and hence, their corresponding referents. Besides, it aligns itself more with the generalist view on disciplinarity that assumes that all disciplines are common in terms of their rhetorical and discoursal choices. The approach offers an insight into how conventions, norms and epistemologies shared by the broad knowledge domains influence

\footnotetext{
1 Osei, Yaw Akoto. Individualities in the Referents of I, We, and You in Academic Lectures across Disciplines. Iranian Journal of English for Academic Purposes 9(4). (2020b):1-14; Osei, Yaw Akoto, Juliet O-A Ansah. \& Emmanuel A. Fordjour. Personal Pronouns in Classroom: A Corpus-Based Study of I, We and You in University Lectures across Disciplines. Journal of Languages for Specific Purposes (JLSP). (2021): 53-66; Salmah, B. Yaakob, A Genre Analysis and Corpus-Based Study of University Lecture Introductions. Unpublished Doctoral Dissertation. (UK: The University of Birmingham. 2013), pp. 1-26; Jiin-Yih, Yeo. \& Su-Hie, Ting, Personal Pronouns for Student Engagement in Arts and Science Lecture Introductions. English for Specific Purposes 34. (2014): 26-37.
} 
the referents of the tri-PP, culminating into tri-PP referents that transcend individual DS boundaries. While this approach is crucial in the teaching of English for Academic Purposes (EAP), it does not present the full realities of some referents $I$, we and you shared by two DSs only.

Consequently, this study adopts a microscopic approach to exploring the referents of the tri-PP shared by two DSs only. This approach leans more towards the variationist view that rejects the notion that academic discourse is "monolithic, predictable, and invariant". ${ }^{2}$ More so, it distinguishes between metadiscursive and non-metadiscursive tri-PP and separately accounts for their corresponding referents. The distinction between the referents of metadiscursive and non-metadiscursive tri-PP is useful as it reveals the synergy of the discourse internal and external selves in classroom interaction. ${ }^{3}$ It will also help students to appreciate the proposition made emanating from or concerning metadiscursive and non-metadiscursive selves or identities. ${ }^{4}$ Interestingly, such referents at the intersection of two DSs will further deepen understanding on the "degree of cross-disciplinary diversity..." towards establishing the "patterns of referentiality" or the "territory of reference" of the tri-PP in L2 classroom discourse.

\section{CORPUS AND METHODOLOGY}

This paper aims to examine the discourse referents common to $I$, we and you (tri-PP) across the three disciplinary supercommunities (DSs): Humanity (HS), Social (SS) and Natural (NS) Sciences based on a corpus of academic lectures from an L2 context.

The laborious, time consuming, and expensive nature of developing a spoken corpus has caused many researchers to utilize already existing and readily available corpora. ${ }^{8}$ Some researchers resort to existing corpora because it may be needless to create a new corpus when there is an available one that can answer their research questions. ${ }^{9}$ With the present study aiming to examine the discourse referents of $I$, we and you in Ghanaian university classroom lectures, there was the need to create a corpus that is absolutely Ghanaian.

The authors, therefore, audio-recorded undergraduate academic lectures from two public universities in Ghana, namely Kwame University of Science and Technology-Kumasi and the University of Cape Coast Cape Coast. All the included lectures were from Ghanaian Senior Faculties, regular undergraduate students, spontaneous (not scripted), first semester introductory courses, and English-medium. The lectures were manually transcribed (guided by transcription conventions adapted and processed into computer-readable form. ${ }^{10}$ Given that the focus of the paper is on the tri-PP used by lecturers, only the lecturer-inputs in the lecturer-student classroom interaction were included in the corpus.

2 Joseph, B. A. Afful. The Rhetoric of Undergraduate Student Writing in A Ghanaian University: A Cross Disciplinary Study,. (Saarbrucken: Lambert Academic Publishing. 2010), 123-129.

3 Osei, Y. Akoto. Metadiscourse within a Discipline: A Study of Introduction and Literature Review Chapters of Sociology Masters' Theses. Indonesian Journal of Applied Linguistics 10(2). (2020a): 471-480.

4 Osei, Yaw. Akoto. Metadiscourse Use in English Language and Sociology Master's Theses Literature Review Chapters. ESP World. 57(21). (2019): 1-31; Akoto. Metadiscourse Within a Discipline, 471-480; Osei, Y. Akoto. \& Joseph, B. A. Afful. Variations in Metadiscourse Use in English Language Introduction and Literature Review Thesis Chapters. Language Literacy 4(2). (2020): 390-408; Akoto, Ansah \& Fordjour, Personal Pronouns in Classroom, 53-66; Ken, Hyland. Academic Discourse: English in a Global Context, (London: Continuum. 2009),10-15.

5 Ken, Hyland. Disciplinary Discourses: Social Interactions in Academic Writing, (London: Longman. 2000),12-13.

${ }^{6}$ Joanne, Scheibman. Inclusive and Exclusive Patterning of the English First Person Plural: Evidence from Conversation. Language, Culture and Mind. (2004): 377-396.

7 Akio, Kamio. English Generic We, You, and They: An Analysis in Terms of Territory of Information. Journal of Pragmatics 33. (2001): 1111-1124.

8 Gwyneth, Fox. A Comparison of 'Policespeak' and 'Normalspeak': A Preliminary Study. In: J.M. Sinclair, M. Hoey and G. Fox (eds), Techniques of Description. Spoken and Written Discourse. A Festschrift for Malcolm Coulthard (London and New York: Routledge. 1992),56-58; Charles, F. Meyer. English Corpus Linguistics: An Introduction. (Cambridge: Cambridge University Press. 2002); Yaakob. A Genre Analysis and Corpus-Based Study of University Lecture Introductions.

9 Tony, McEnery. \& Andrew, Hardie. Corpus Linguistics: Method, Theory and Practice, (Cambridge: Cambridge University Press. 2012),10-13.

${ }_{10}$ Rita, C. Simpson., Sarah, L. Briggs., Janine, Ovens. \& John, M. Swales. The Michigan Corpus of Academic Spoken English, (Ann Arbor: The Regents of the University of Michigan. 2002),21-26. 
Table 1: Disciplinary Supercommunities and Subcorpora Word Counts

\begin{tabular}{|c|c|}
\hline Disciplinary Supercommunities & Word Counts \\
\hline $\begin{array}{l}\text { Humanities } \\
\text { English Language } \\
\text { Philosophy } \\
\text { Religious Studies }\end{array}$ & 36586 \\
\hline $\begin{array}{l}\text { Social Sciences } \\
\text { Law } \\
\text { Communication Studies } \\
\text { Political Science } \\
\text { Educational Foundations }\end{array}$ & 43916 \\
\hline $\begin{array}{l}\text { Natural Sciences } \\
\text { Electrical Engineering } \\
\text { Mathematics } \\
\text { Biology }\end{array}$ & 34622 \\
\hline Total & 115124 \\
\hline
\end{tabular}

Table 1 shows the DSs and the individual disciplines, the sizes of the subcorpora and the overall total. Admittedly, the size of the corpus is relatively small. Lee has opined that the size of a corpus matters in research. ${ }^{11}$ This has engendered debate among corpus linguists. Some scholars advocate a large corpus study, arguing that this provides a realistic representation of the occurrence of the use of a particular linguistic variable and that small corpora 'impose certain limitations on the generalizability of the findings' ${ }^{12}$ Fox therefore, asserts that '...the bigger the corpus, the more chance there is of finding examples which are both natural and meaningful...'13 Fox's position re-echoes the maxims 'small is not beautiful; ${ }^{14}$ it is simply a limitation' ${ }^{15}$ and 'the lengthier the corpus, the better' ${ }^{16}$ While this is true to some extent, Koester ${ }^{17}$ asserts that mega-corpus usually suffers superficial analysis.

In spite of the immense contribution of large corpora mainly concerning the fuzzy and the debated term representativeness, smaller specialized corpora have been found to be useful in language studies, to reflect the pattern of some linguistic variables, especially functional words. The variables under investigation (I, we and you) largely have an implication on the corpus size. Arguably, it is more useful to use a small corpus in exploring a functional item than a lexical or content one. ${ }^{18}$ Thus, in exploring $I$, we and you in this study,

\footnotetext{
${ }^{11}$ Joseph, J. Lee. Size Matters: An Exploratory Comparison of Small and Large Class University Lecture Introductions. English for Specific Purposes 28(1). (2009): 42-57.

12 Anne, O’keeffe., Michael, McCarthy. \& Ronald, Carter. From Corpus To Classroom, (Cambridge: Cambridge University Press. 2007),48-51; Fox. A Comparison of 'Policespeak' and 'Normalspeak': A Preliminary Study. 40-72; John, Sinclair. \& Roland, Carter. Trust the Text: Language, Corpus and Discourse, (New York: Routledge. 2004),40-42; James. W. Blackwell. The TextCompositional Architecture of University Lectures: An Exploration of Genre and Periodicity in Spoken Academic Discourse: Unpublished Doctoral Dissertation. (UK: The University of Birmingham. 2010).

13 Fox. A Comparison of 'Policespeak' and 'Normalspeak': A Preliminary Study, (pp. 40-72).

14 Fox. A Comparison of 'Policespeak' and 'Normalspeak': A Preliminary Study, (pp. 40-72).

15 Sinclair. \& Carter. Trust the Text: Language, Corpus and Discourse, 35-37.

${ }_{16}$ Meyer. English Corpus Linguistics: An Introduction, 1-5.

17 Almut, Koester. Building Small Specialised Corpus. In A. O’Keeffe \& M. McCarthy (Eds.). The Routledge Handbook of Corpus Linguistics (London: Routledge. 2010),66-79.

18 Koester. Building Small Specialised Corpus, 66-79.
} 
one does not require a relatively large corpus to obtain occurrences that are 'representative of typical use'19 since pronouns are considered high-frequency items. ${ }^{20}$ Surely, on functional items in corpus-based studies, contrary to Sinclair and Carter's ${ }^{21}$ contention, small becomes beautiful, and simply not a limitation.

With a large corpus, the compilers are usually not the analysts and so they (analysts) appear to be unfamiliar with some useful contextual clues to the corpus. However, Koester ${ }^{22}$ rightly contends that 'with small corpus, the corpus compiler is often also the analyst, and therefore usually has a high degree of familiarity with the context'. This is true with the current study, as the authors adopted an ethnographic approach in collecting the data. Consequently, they personally observed contextual information on the number of teachers (as some lecturers went with their Teaching Assistants), lecturing style and class size which cannot be inferred from the corpus.

\section{Corpus analysis}

This research used the concordance tool in AntConc (v.3.5.0) to search for the tri-PP in the corpus. ${ }^{23}$ Baker et al. observe that "concordance analysis affords the examination of language features in co-text, while taking into account the context that the analyst is aware of and can infer from the co-text". ${ }^{24}$ The researchers then manually examined each 'occurrence' to determine: one, its 'pronounness' as in 'I' in the name 'I K Abban' from the SS subcorpus, and two, referents. All cases of $I$, you and we, and their corresponding variants were searched and examined to ascertain their referents. The discourse referents were mainly determined based on the contextual and co-textual information surrounding the tri-PP. The researchers closely examined the concordance lines of each of the tri-PP, guided by "the collocating verbs associated with the pronouns ... to obtain contextual and linguistic cues". ${ }^{25}$ Ädel observes: "there are oftentimes contextual clues present in the data which reveal something about the scope of a pronoun". ${ }^{26}$

The analysis generally revealed the 'territory of reference' or 'patterns of referentialities' of $I$, we and you (tri-PP) within and across the Ds, represented by Figure 1.

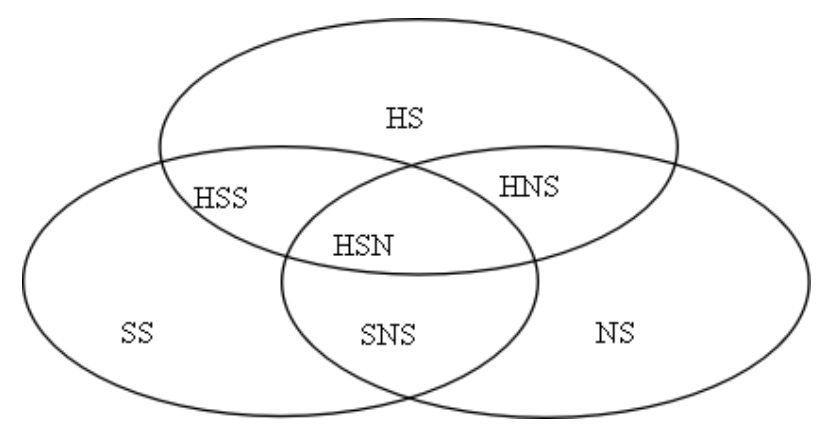

Figure 1: DS interrelationships

The sections labelled HS, SS and NS show the DS-specific referents of the tri-PP. Discourse referents that appear in these sections reveal the distinctiveness of an individual DS, and Akoto's study focused on this. ${ }^{27} \mathrm{He}$ found that there are some referents of the tri-PP that are specific to each of the broad knowledge

\footnotetext{
19 Fox. A Comparison of 'Policespeak' and 'Normalspeak': A Preliminary Study, 40-72.

${ }^{20}$ Koester. Building small specialised corpus, 66-79.

21 Sinclair. \& Carter. Trust the Text: Language, Corpus and Discourse, pp. 99-102.

22 Koester. Building Small Specialised Corpus, 66-79.

${ }^{23}$ Laurence, Anthony. AntConc (Version 3.5.0) [Computer Software]. Tokyo, Japan: Wased University. (Available from http://www.laurenceanthony.net. 2015).

24 Paul, Baker., Gabrielatos, Costas., Majid, Khosravinik., Michał, Krzyżanowski., Tony, McEnery. \& Ruth, Wodak. A Useful Methodological Synergy? Combining Critical Discourse Analysis and Corpus Linguistics to Examine Discourses of Refugees and Asylum Seekers in the UK Press. Discourse and Society 19(3). (2008): 273-306.

25 Yeo \& Ting. Personal Pronouns for Student Engagement in Arts and Science Lecture Introductions,26-37.

26 Annelie, Ädel. Just to Give You Kind of a Map of Where We Are Going: A Taxonomy of Metadiscourse in Spoken and Written Academic English. Nordic Journal of English Studies 9(2). (2010): 69-97.

${ }_{27}$ Akoto. Individualities in the Referents of I, We, and You in Academic Lectures Across Disciplines, 1-14.
} 
domains. Further, the sections marked HSS, HNS and SNS indicate the inter-DS commonalities in the tri-PP referentialities. Such referents are shared by two DSs. Finally, the section marked HSN represents the point of convergence of the three DSs. But as has already been reiterated, the research examined the referents within HSS, HNS and SNS only.

Having determined the referents, the researchers counted the occurrences of the referents of the tri-PP, and these were normalized to occurrences per 1,000 words (ptw), given that the subcorpora, as shown in Table 1, had unequal sizes. Finally, they conducted a log-likelihood analysis using Rayson's Log-likelihood calculator to determine whether the observed differences were statistically significant. They used $95^{\text {th }}$ percentile; $5 \% ; \mathrm{p}$ $<0.05$, with log-likelihood value $=3.84$ as the 'cut-off point of statistical significance' implying that any value equal or above 3.84 was deemed statistically significant. ${ }^{28}$

\section{RESULTS AND DISCUSSION}

This section discusses the results on the referents of the tri-PP at the interface of two DSs: HS vs SS, HS vs NS and SS vs NS.

\section{I-referents}

This subsection discusses the referents of $I$ at the interfaces of two DSs. It is important to note that while there are HS-SS and SS-NS commonalities, there is zero I-referent shared by HS and NS. This seems to support the tacit proximity hypothesis that underpins cline-based disciplinary classification models such as Becher \& Trowler, Hyland and MacDonald. ${ }^{29}$ It is shown in such models that the degree of proximity affects the choice of shared discoursal/rhetorical features.

\section{I-referents specific to HS and NS}

Table 2 shows I-referents common to HS and SS, and these are I for political figures and I for lecturer as a child. These referents are non-metadiscursive such that they refer to non-ratified absentee participants outside the discourse internal world.$^{30}$ Interestingly, they are both anthropocentric (i.e. human-related), affirming the centrality of humans in the discourses of HS and SS. ${ }^{31}$ I for lecturer then a child is instantiated in the extracts HSC 0004 and SSC 0005, while I for political figures is also exemplified in HSC 0005 and SSC 0006.

HSL: Because growing up in a typical village $\underline{\mathbf{I}}$ go to, $\underline{\mathbf{I}}$ go to the farm, $\underline{\mathbf{I}}$ come with cassava, okay. [HSC 0004]

SSL: So that is how we ended up in Nigeria and $\underline{\mathbf{I}}$ had my early primary in Nigeria. $\underline{\mathbf{I}}$ came back only for the secondary school. [SSC 0005]

The non-metadiscursive $I$-referents exemplified in the above extracts challenge Biber and Conrad's claim that "pronouns refer to things that are present in the communication situation: oneself, the listener, other people or objects. Such people and objects exist in the situational context for classroom teaching...".32

Table 2: I-referents specific to HS and SS

\begin{tabular}{lllc}
\multicolumn{1}{c}{ Referents } & HS: RF(NF) & \multicolumn{1}{c}{ SS: RF(NF) } & LL \\
\hline Political figures (e.g. Kwame Nkrumah) & $1(0.27)$ & $9(2.05)$ & 5.98 \\
Lecturer then a child & $11(3.01)$ & $2(0.46)$ & 8.61 \\
\hline
\end{tabular}

*A log-likelihood greater than 3.84 indicates a p-value less than 0.05 .

${ }_{28}$ Baker., et al A Useful Methodological Synergy? 273-306.

29 Susan, P. MacDonald. Professional Academic Writing in the Humanities and Social Sciences. (Carbondale: Southern Illinois University Press. 1994); Tony, Becher. \& Paul, Trowler. Academic Tribes and Territories ( $2^{\text {nd }}$ ed.) (Buckingham: The Open University Press. 2001),151-161; Ken, Hyland. Academic Discourse: English in a Global Context, (London: Continuum. 2009), 18-23.

${ }^{30}$ Erving, Goffman. The Presentation of Self in Everyday Life, (New York: Doubleday Anchor. 1981), 14-17; Annelie, Ädel Metadiscourse in L1 and L2 English, (Philadelphia: John Benjamins. 2006),73-78; Ken, Hyland. Stance and Engagement: A Model of Interaction in Academic Discourse. Discourse Studies 7(2). (2005):173-192.

31 Becher. Academic Tribes and Territories, 151-161.

32 Douglas, Biber. \& Susan, Conrad. Register, Genre, and Style, (Cambridge: Cambridge University Press. 2009),87-95. 
In HSC 0004 and SSC 0005, lecturers reminisced their childhood days and tapped into such experiences for emphasis. In HSC 0004, for instance, the lecturer recounted how he went to the farm and came home with cassava which was exchanged for plantain or other 'goods' from their neighbours. The lecturer, therefore, drew on that to substantiate the African concept of communalism which underpinned the practice of barter trade and the Akan concept of personhood in the pre-colonial African societies. ${ }^{33}$

On the other hand, both HS and SS used $I$ to refer to some political figures. With respect to pronounpronoun mapping, this $I$ is $I$ for he as in HSC 0005; and $I$ for $I$ (non-discoursal speaker) as in SSC 0006.

HSL: The other time I made it clear that even when he started his duty as the General Secretary, Nkrumah for some time was not being paid but he was indifferent about money and so he went ahead and promised his staff and the General Secretary of the UGCC not thinking about whether he was paid and having the interest of the people at heart, ensuring that the independence, political independence of the people had been achieved without thinking about what $\underline{\mathbf{I}}$ am receiving in the form of money. [HSC 0005]

SSL: Anyway so they came to see my dad so that he can actually be with the CPP instead of UP... You know I'm not moving. This is $\underline{\mathbf{m y}}$ party. [SSC 0006]

Using I for themselves and political figures (I for helthey) suggests the complex footing employed by HS and SS lecturers in using $I$. This discursive strategy resonates with Bakhtin's ventriloquation, ${ }^{34}$ echoed coincidentally in the same year by Goffman. ${ }^{35}$ Largely, the common denominators to HS and SS affirm their closeness as having dispersed knowledge. ${ }^{36}$ Thus, they draw on such retrospective referents to accumulate such historical disciplinary dispersed knowledge.

\section{I-referents specific to SS and NS}

Interestingly, I as practitioner in the field was found to be SS-NS specific, as shown in Table 3.

Table 3: I-referents Peculiar to SS and NS

\begin{tabular}{cccc}
\hline Referents & SS: $\mathbf{R F}(\mathbf{N F})$ & NS: RF(NF) & LL \\
\hline Practitioners in the field & $6(1.37)$ & $20(5.78)$ & 11.65 \\
\hline
\end{tabular}

*A log-likelihood greater than 3.84 indicates a p-value less than 0.05 .

The Social and Natural Scientists attempted to evoke the presence of threshold practitioners in their lectures to show students the relatively bridged relation between academia and industry. ${ }^{37}$ Thus, students are educated to understand the applicability of the knowledge acquired. I for practitioners is exemplified in corpus evidence SSC 0007 and NSC 0004.

SSL: If it's being upheld, if somebody is a er makes application to the court, $\underline{\mathbf{I}}$ want a declaration, for $X$ the court says erh your submission has been upheld...[SSC 0007]

NSL: Then, if $\underline{\mathbf{I}}$ happen to calculate effort to be equal to twenty, how many young engineers will $\underline{\mathbf{I}}$ 0004]

In the above extracts, the marked $I$-forms do not refer to the lecturer, student, or both. They allude to nondiscoursal participants, which are a legal practitioner (in SSC 0006), and a practicing engineer (in NSC 0004). Thus, the $I$-forms marked as $I$ for practitioners are non-metadiscursive, because they make reference

\footnotetext{
33 Kwame Gyekye, The Akan Concept of a Person. In A. R. Wright (Ed.). African Philosophy: An Introduction, (Lanham, Md.: University Press of America. 1984), 101-122.

${ }^{34}$ Mikhail, M. Bakhtin. The Dialogic Imagination: Four Essays. In M. Holquist, Ed.; \& C. Emerson \& M. Holquist, Trans, (Austin: University of Texas Press. 1981)66-69.

35 Goffman. The Presentation of Self in Everyday Life, 10-17.

${ }^{36}$ Ken, Hyland. Academic Discourse: English in a Global Context, 77-82.

${ }^{37}$ Afful, The Rhetoric of Undergraduate Student Writing in a Ghanaian University, 22-28.
} 
to entities in the real world..$^{38}$ It is, therefore, not surprising that in his cognitively-based model of disciplinary typology, Biglan classified most of NS and SS disciplines as applied and all HS ones as pure. ${ }^{39}$

The studies that reported findings close to the present one are Zhihua ${ }^{40}$ who found I for anyone in the field; and Rounds' I for mathematicians. ${ }^{41}$ It is important to note that the terms used in the studies (the present and the previous ones) connote different referents. Zhihua's I for anyone in the field encompasses the present study's practitioners in the field and some other disciplinary discourse communities aligned members such as Teaching Assistants, Research Assistants and Graduate Assistants. ${ }^{42}$ Furthermore, Rounds' $I$ for mathematicians partly relates to I for practitioners in this study, since a mathematician could be either an academic or a professional, what we refer to as scholars and practitioners respectively. ${ }^{43}$

\section{We-referents}

This sub-section discusses the occurrence and usage of we-referents identified in the data.

\section{We-referents specific to $H S$ and $S S$}

There are some we-referents common to HS and SS. These are mainly toponyms (Africa and Ghana) and geographic anthroponyms (Africans and Ghanaians).

\section{Table 4: We-referents Peculiar to HS and SS}

\begin{tabular}{llll}
\hline Referents & HS: RF(NF) & SS: RF(NF) & LL \\
\hline Ghana(ians) & $22(6.01)$ & $16(3.64)$ & 2.36 \\
Africa(ns) & $35(9.57)$ & $62(14.12)$ & 3.49 \\
\hline
\end{tabular}

*A log-likelihood greater than 3.84 indicates a p-value less than 0.05 .

HS and the SS compared to the NS are considered more anthropocentric and society-centred. ${ }^{44}$ Hyland also maintains that HS and SS have a more varied audience as compared to NS which has a concentrated audience. ${ }^{45}$ Additionally, HS and SS are perceived to draw more on discourse external events than NS. ${ }^{46}$ It is, therefore, not surprising to find HS and SS employing we to refer to countries and continents and their associated anthroponymic references. The we in extracts HSC 0010 and SSC 0013, corresponds with Africa(ns), and Ghana(ians) respectively.

HSL: And uuuhm, most of the values $\underline{\mathbf{w e}}, \underline{\mathbf{w e}}, \underline{\mathbf{w e}}$ used to have or we claim to have, now have been thrown... [HSC 0010]

SSL: So although we had a written constitution, we did not have constitutional supremacy. [SSC 0013]

This finding is peculiar to the present study, as none of the studies on we-referents reported on this. This affirms the effect of geopolitics on academic discourse as this study found out that Humanity and Social Scientists enact socio-academic identities through the discourse-defined we-referents. ${ }^{47}$ Tuathail and Agnew

\footnotetext{
38 Ädel. Metadiscourse in L1 and L2 English, 6-19; Ken, Hyland. Stance and Engagement: A Model of Interaction in Academic Discourse. Discourse Studies 7(2). (2005):173-192.

39 Anthony, Biglan. Relationships Between Subject Matter, Characteristics and The Structure and Output of University Departments Journal of Applied Psychology 57(3). (1973): 207-213.

${ }^{40}$ Guo, Zhihua. The Use of Personal Pronouns in University Lectures. (Paper presented at University of Applied Sciences Language Structure and Language Learning Conference. 2011).

41 Patricia, L. Rounds. Multifunctional Personal Pronouns Use in Educational Setting. English for Specific Purposes 6(1). (1987): 13-29.

42 Zhihua. The Use of Personal Pronouns in University Lectures, 14-21.

43 Rounds. Multifunctional Personal Pronouns Use in Educational Setting, 13-29.

44 Afful. The Rhetoric of Undergraduate Student Writing in a Ghanaian University: A Cross Disciplinary Study, 9-12; Tony, Becher. $\&$ Paul, Trowler. Academic Tribes and Territories ( $2^{\text {nd }}$ ed.). (Buckingham: The Open University Press. 2001).

45 Ken, Hyland. Academic Discourse: English in a Global Context, (London: Continuum. 2009),167-168.

46 Ädel. Just to Give You Kind of a Map of Where We Are Going,69-97; Ädel, Metadiscourse in L1 and L2 English.

47 Ken, Hyland. Options of Identity in Academic Writing. ELT Journal 56(4). (2002b): 351-358.
} 
define geopolitics "as a discursive practice by which intellectuals of statecraft 'spatialize' international politics and represent it as a 'world' characterized by particular types of places, peoples and dramas". ${ }^{48}$ Thus, the finding is congruent with the social constructivist ideology which largely underpins the discourses of the HS and SS -contrary to NS which is inspired by the positivist ideology. ${ }^{49}$

It is important to note that there is no we-referent common to HS and NS. This could be explained by the distance between them based on their position on the linear representation of the three broad knowledge domains. ${ }^{50}$ While this can provide a loose justification, the study cannot stretch the argument so much, given that in spite of their distance, disciplines (such as medical humanities, bioethics, neurolinguistics, are increasingly emerging from the two perceived 'irreconcilable' knowledge domains.

\section{We-referents specific to SS and NS}

We as practitioners in the field and lecturers + general students + scholars in the field are found to be peculiar to SS and NS, as shown in Table 5.

Table 5: We-referents Peculiar to SS and NS

\begin{tabular}{llll}
\hline SS vs NS & SS: RF(NF) & NS: RF(NF) & LL \\
\hline Practitioners in the field & $14(3.19)$ & $13(3.75)$ & 0.18 \\
Lecturer + all students + all scholars in the field & $49(11.16)$ & $51(14.73)$ & 1.93 \\
\hline
\end{tabular}

*A log-likelihood greater than 3.84 indicates a p-value less than 0.05 .

The difference among we for scholars in the field + lecturer + students and other related ones is based on the degree of attachment of the speaker (lecturer) to the proposition made. The practitioners in the field, on the other hand, refer to what Afful terms as threshold practitioners. ${ }^{51}$ We for practitioners in the field indicates the desire of SS and NS lecturers to invoke in their students the community of practice that awaits the students after school. ${ }^{52}$ It can be perceived as a strategic step by these lecturers to integrate academic discourse community (theory) and community of practice (practice) to signify their interdependence. By doing this, these "lecturers not only facilitated understanding, but also introduced learners to what kind of knowledge is important and how it is negotiated within the community of practice" (Emphasis mine). ${ }^{53}$

Unsurprisingly, in her extensive study into the language of business lectures, specifically Economics (a Social Science discipline), Crawford Camiciottoli revealed that lecturers enact professional identities in their lectures, ${ }^{54}$ which resonates with the view that both NS and SS are more practice-oriented than the HS. ${ }^{55}$ The absence of these in the HS is hard to explain. However, Hyland argues that "the sciences see knowledge as a cumulative development from prior knowledge accepted on the basis of experimental proof" and next to NS on the 'ideological continuum' is SS. ${ }^{56}$ Thus, their recognition of the practitioners in the field is quite justifiable.

\footnotetext{
${ }^{48}$ Gearóid, Ó. Tuathail. \& John, Agnew. Geopolitics and Discourse: Practical Geopolitical Reasoning in American Foreign Policy. Political Geography 11(2). (1992): 190-204.

49 Hyland, Options of Identity in Academic Writing, 351-358.

${ }^{50}$ Hyland, Options of Identity in Academic Writing, 351-358.

51 Afful. The Rhetoric of Undergraduate Student Writing in a Ghanaian University, 56-58.

${ }^{52}$ Osei, Y. Akoto. \& Benjamin, Amoakohene. Exploring Wordless Feedback Mechanisms in an EAP Course in an English-Medium University: An Ethnographically-Oriented Approach. Journal of English Language Teaching and Applied Linguistics 2(4). (2020): 50-61; Camiciottoli, B. Crawford. The Languages of Business Studies Lectures, (Amsterdam: John Benjamins. 2007 )1-7.

53 Camiciottoli, B. Crawford The Languages of Business Studies Lectures, 3-9.

${ }^{54}$ Camiciottoli, B. CrawfordThe Languages of Business Studies Lectures, 52-56.

55 Tony, Becher. The Significance of Disciplinary Differences. Studies in Higher Education 19(2). (1994):151-161; Biglan. Relationships Between Subject Matter, C 207-213; Jerome, Kagan. The Three Cultures: Natural Sciences, Social Sciences, and the Humanities in the 21 st Century. (Cambridge: Cambridge University Press. 2009).

56 Hyland. Academic Discourse: English in a Global Context, 100-102.
} 
SSL: So we have to we have to put it before we put it into the context, and by the time that context comes by the time that context comes, listeners may have forgotten what they were supposed to remember. [SSC 0014]

NSL: So we use these things in decision making as in engineers as we go out there. [NSC 0009]

Similar to written academic discourse where literature and authorities are cited, NS and SS allude to the scholars in the field as scholars in charge of the 'knowledge economy' and the practitioners as the implementers of the generated knowledge in real life to solve practical problems. The two we referents reported here seem novel as it is only Zhihua ${ }^{57}$ who found anyone in the field which is broader than what we have found in this study. Zhihua's term seems vague as it can designate all the members of the academic discourse community: students, experts and threshold practitioners. ${ }^{58}$

\section{You-referents}

Interestingly, with respect to you-referents, there are some HS-SS, HS-NS, and SS-NS shared ones. From Tables 6, 7 and 8, there are 7,1 and 2 you-referents common to HS-SS, HS-NS and SS-NS respectively.

\section{You-referents specific to HS and SS}

It is noticed from Table 6 that there are some HS-SS you-referents that cast retrospective (e.g. current students when pupils), current (e.g. female students) and prospective (e.g. current students when they become graduates) identities, re-echoing the first part in Jones ${ }^{59}$ RA title: "The way we were, are and might be". ${ }^{60}$

Table 6: You-referents Peculiar to HS and SS

\begin{tabular}{lccc}
\hline \multicolumn{1}{c}{ Referents } & HS: RF(NF) & SS: RF(NF) & LL \\
\hline Female students & $1(0.27)$ & $1(0.23)$ & 0.02 \\
Lecturer+ scholars in the field & $7(1.91)$ & $9(2.05)$ & 0.02 \\
Current students when pupils & $4(1.09)$ & $1(0.23)$ & 2.52 \\
Students of an institution (e.g. UCC) & $3(0.82)$ & $4(0.91)$ & 0.02 \\
Country & $1(0.27)$ & $9(2.05)$ & $* 5.98$ \\
General students in the field & $8(2.19)$ & $15(3.42)$ & 1.08 \\
Current students when become graduates & $6(1.64)$ & $8(1.82)$ & 0.04 \\
\hline
\end{tabular}

*A log-likelihood greater than 3.84 indicates a p-value less than 0.05 .

HS and SS's shared desire to navigate through the time dimensions (present, past and future) can be attributed to the shared "norms of enquiry, qualitative and the common interpretive approach". ${ }^{61}$ The qualitative research paradigms allow the Humanity and Social Scientists to construct the three-pronged time-based identities of the audience. Both broad disciplinary domains are said to have more fluid discourses that offer the lecturers the flexibility to draw on intertextual as well as discourse external realities. But the allusion to discourse-external realities is not peculiar to HS/SS; we find HS and NS also referring to the past of the current student. These are attempts by lecturers to reinforce the cumulative nature of knowledge and, therefore, academic maturity.

\section{You-referents specific to HS and NS}

The retrospective use of you to designate the student's pre-tertiary status (specifically, at the Senior High School [SHS]) was found to be common to HS and NS. It indicates that both HS and NS lecturers cause their students to reminisce their pre-tertiary studentship experiences. This discursive referent reminds students of the cumulative nature of knowledge, which can be transferred to the tertiary level for the sake of epistemic progression into their respective discourse communities.

57 Zhihua. The Use of Personal Pronouns in University Lectures..

58 Zhihua. The Use of Personal Pronouns in University Lectures, 116-119.

59 Stacy, H. Jones. The Way We Were, Are And Might Be: Torch Singing as Autoethnography. In A. P. Bochner \& C. Ellis (Eds Ethnographically Speaking: Autoethnography, Literature, and Aesthetics (Walnut Creek: AltaMira Press. 2002) 44-56.

60 Jones. The Way We Were, Are And Might Be: Torch Singing as Autoethnography, 44-56.

${ }^{61}$ Rosemary, Clerehan., Tim, Moore. \& Sheila, Vance. Collaborating in the Transition to Tertiary Writing. ASCILITE (2001): 125 132; Hyland, Academic Discourse: English In A Global Context, 111-119. 


\section{Table 7: You-referents Peculiar to HS and NS}

\section{Referents \\ HS: RF(NF)

NS: RF(NF) LL

\begin{tabular}{llll}
\hline Current students when at SHS & $5(1.37)$ & $11(3.18)$ & 2.65 \\
\hline
\end{tabular}

*A log-likelihood greater than 3.84 indicates a p-value less than 0.05 .

Querol Julian describes this kind of referent as "a reference to student's background knowledge". ${ }^{62}$ This rhetorical reference inspires students to tap into their accumulated knowledge on the subject matter under consideration. The finding corroborates Yeo and Ting's realization that you is used to activate students' prior knowledge.

\section{You-referents specific to SS and NS}

Table 8 indicates that you for practitioners in the field and SHS students are peculiar to SS and NS. While you for SHS students appear difficult to be justified, you for practitioners is unsurprising.

Table 8: You-referents Peculiar to SS and NS

\begin{tabular}{|c|c|c|c|}
\hline Referents & SS: & NS: RF(NF) & $\mathbf{L L}$ \\
\hline Practitioners in the field & $\begin{array}{l}\mathbf{R F}(\mathbf{N F}) \\
5(1.14)\end{array}$ & $69(19.93)$ & $* 82.25$ \\
\hline SHS students & $3(0.68)$ & $1(0.29)$ & 0.63 \\
\hline
\end{tabular}

*A log-likelihood greater than 3.84 indicates a p-value less than 0.05 .

Afful considered practitioners in the field as members of the academic discourse community. ${ }^{63}$ This shared referent can be attributed to the comparatively high degree of applicability of knowledge in SS and NS. Arguably, every DS has both theoretical and applied components. ${ }^{64}$ Biglan shows that SS and NS engage in knowledge application than HS, which is used to uphold the mantra scientia gratia scientiae (i.e. knowledge for knowledge sake). ${ }^{65}$ Interestingly, the log-likelihood test shows that disciplinary variation affects this referent use as the LL (82.25) value is exceedingly above the significance cut-off point - LL 3.84. NS lecturers' high patronage of this referent is not surprising as it is labelled as a highly applied knowledge domain. ${ }^{66}$

\section{FINDINGS}

The paper investigated the discourse referents of I, we and you (tri-PP) through a 'microscopic lens' to establish the referents of the tri-PP at the interface of two DSs. Drawing on Hyland's model that clusters disciplines into Natural, Social and Humanity Sciences, the research found that some discourse referents were at the intersection of two DSs. ${ }^{67}$ For instance, it was noticed that $I$ was used to designate practitioners and this was common to Natural Sciences and Social Sciences only. The results of this paper have further shown the role inter-disciplinarity on discourse referents of pronominal resources such as $I$, we and you (tri-PP) in classroom spoken lectures in L2 context. While previous studies showed that shared disciplinary conventions, norms and epistemologies influence the discourse referents of the tri-PP across DSs, the present study suggests that shared conventions also affect the discourse referents of the tri-PP at the interface of two DSs. ${ }^{68}$

The study has implications for the field of pedagogical and/or educational linguistics, particularly the triad communication in the classroom (i.e. teacher with student(s), student with teacher, and student

\footnotetext{
${ }^{62}$ Mercedes, Querol-Julián. The Role of Questions in English Academic Lectures. Newcastle Working Papers in Linguistics 14. (2008): 100-111.

63 Afful. The Rhetoric of Undergraduate Student Writing in a Ghanaian University: A Cross Disciplinary Study, 56-58.

${ }^{64}$ Biglan. Relationships Between Subject Matter, 207-213.

65 Biglan. Relationships Between Subject Matter, 207-213.

${ }^{66}$ Biglan. Relationships Between Subject Matter, 207-213.

${ }^{67}$ Hyland. Academic Discourse: English in a Global Context,11-19.

68 Yaakob. A Genre Analysis and Corpus-Based Study of University Lecture Introductions.; Jiin-Yih, Yeo. \& Su-Hie, Ting. Personal Pronouns for Student Engagement in Arts and Science Lecture Introductions. English for Specific Purposes 34. (2014): 26-37.
} 
with student). This paper largely borders on the teacher-student interaction. The findings will help students to appreciate the varied pragmatic nuances of the personal pronouns teachers employ. As Hyland asserts, students understanding of the polypgramatic complexities of the referents of pronouns will enhance their understanding of content knowledge within their respective disciplinary contexts. ${ }^{69}$

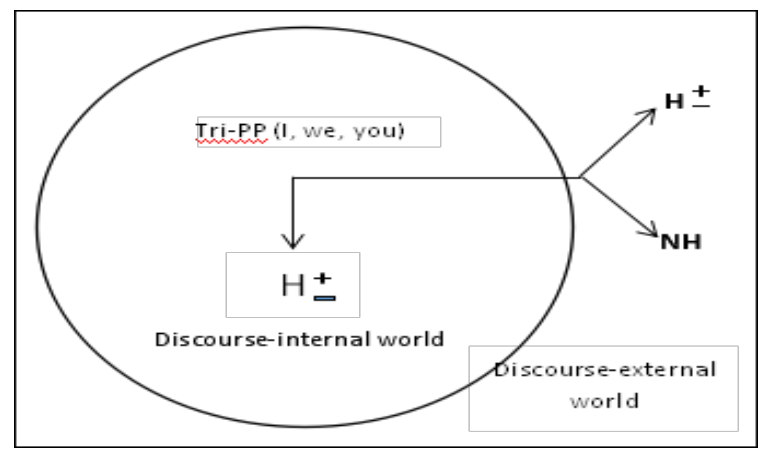

Figure 2: Multireferentiality and multireferencing of I, we and you

More so, the paper shows the extent to which metadiscursive and non-metadiscursive referents are enacted in classroom talks. This further shows the relation between discourse internal and external selves and realities and how they can be synergized to aid students' understanding of some disciplinary concepts. It also has an implication for our understanding of the complexity of the concepts of referencing in relation to personal pronouns particularly in spoken discourse, as shown in Figure 2. Figure 2 shows how the tri-PP points to entities within and outside the text.

Two $\mathrm{H}^{+}$. were observed; one within and one outside the text, which suggest that the tri-PP can designate human and non-human entities within and outside texts, what Ädel refers to as metadiscourse, and participation respectively. ${ }^{70}$

\section{CONCLUSION}

As was realized in this study, $I$, we and you generally designated identities in the discourse external world such as practitioners in the field, scholars in the field, and SHS students. It is, therefore, required of both language and content lecturers, on one hand, and students, on the other hand, to improve upon their pronominal competence in order to help them communicate and understand disciplinary discourses.

Given the relatively smaller size of the corpus for this study, a larger one can be built to further investigate these inter-DS shared referents of $I$, we and you.

\section{ABOUT AUTHORS}

Osei Yaw Akoto (PhD) is a lecturer in the Department of English, Faculty of Social Sciences, College of Humanities and Social Sciences, Kwame Nkrumah University of Science and Technology, Ghana. He holds B.A (Hons) in English Language and Philosophy; M.Phil. and $\mathrm{PhD}$ in English Language, all from the University of Cape Coast, Cape Coast, Ghana. He teaches courses like English for Academic Purposes, Sociolinguistics, Discourse Studies and Error Analysis. His research interest includes Linguistic Landscape, Onomastics, Corpus Linguistics and Academic Discourse. His recent publication appeared in Word.

Dr. Benjamin Amoakohene is a Lecturer at the Department of General and Liberal Studies of the University of Health and Allied Sciences, where he teaches Academic and Communicative Skills. He had his terminal degree in Applied Linguistics from the University of the Western Cape, South Africa. Before becoming a Lecturer at the University of Health and Allied Sciences, Dr. Benjamin Amoakohene had served as a Teaching

\footnotetext{
${ }^{69}$ Ken, Hyland. Authority and Invisibility: Authorial Identity in Academic Writing. Journal of Pragmatics 34. (2002a): 1091-1112; Ken, Hyland. Options of Identity in Academic Writing. ELT Journal 56(4). (2002b): 351-358.

70 Ädel. Metadiscourse in L1 and L2 English, 3-5; Ädel. Just to Give You Kind of a Map of Where We Are Going, 69-97.
} 
Assistant at the Department of English and the Department of Communication Studies of the University of Cape Coast. He has had the privilege to serve as the Examination Officer and the Acting Head of Department at the Department of General and Liberal Studies of the University of Health and Allied Sciences at different times. His areas of research are Genre Studies, Discourse Analysis and Sociolinguistics. He is a member of the Systemic Functional Linguistics group, Ghana and the Linguistic Association of Ghana. He is currently the Organizer for the Ghana Names Society.

Juliet Oppong-Asare Ansah is a lecturer in the Department of Language and Communication Sciences, Faculty of Social Sciences, College of Humanities and Social Sciences, Kwame Nkrumah University of Science and Technology, Ghana. She holds Bachelor of Education in Psychology and Master of Philosophy in Ghanaian Language (both from the University of Cape Coast, Cape Coast Ghana). Currently, she is a PhD candidate in Linguistics at the University of Ghana, Legon, Accra-Ghana. She has been teaching courses like Semantics, Aesthetics of Oral Literature, Translation, Creative Writing, Pragmatics and Akan Written Expression. Her research interest includes Ethnographic Linguistics, Diachronic Studies, Semantics and its interfaces, Language Contact and Translation Studies. Her latest article published by Noyam is on the use of persuasion in Christian fundraising.

\section{BIBLIOGRAPHY}

Ädel, Annelie. Just to give you kind of a map of where we are going: A taxonomy of metadiscourse in spoken and written academic English. Nordic Journal of English Studies 9 no. 2, (2010): 69-97.

Ädel, Annelie. Metadiscourse in L1 and L2English. (Philadelphia: John Benjamins. 2006).

Afful, Joseph. Benjamin. A. The rhetoric of undergraduate student writing in a Ghanaian university: A cross disciplinary study. (Saarbrucken: Lambert Academic Publishing. 2010).

Akoto, Osei. Yaw. \& Afful, Joseph. Benjamin. A. Variations in metadiscourse use in English Language introduction and literature review thesis chapters. Language Literacy 4 no. 2, (2020): 390-408.

Akoto, Osei. Yaw. \& Amoakohene, Benjamin. Exploring wordless feedback mechanisms in an EAP course in an English-medium university: An ethnographically-oriented approach. Journal of English Language Teaching and Applied Linguistics 2 no. 4, (2020): 50-61.

Akoto, Osei. Yaw. Individualities in the referents of I, we, and you in academic lectures across disciplines. Iranian Journal of English for Academic Purposes 9 no. 4: 1-14. (2020b).

Akoto, Osei. Yaw. Metadiscourse within a discipline: a study of introduction and literature review chapters of sociology masters' theses. Indonesian Journal of Applied Linguistics 10 no. 2, (2020a): 471-480.

Akoto, Osei. Yaw., Ansah, Juliet. O-A. \& Fordjour, Emmanuel. A. Personal pronouns in classroom: a corpusbased study of I, we and you in university lectures across disciplines. Journal of Languages for Specific Purposes (JLSP) (2021): 53-66.

Anthony, Laurence. AntConc (version 3.5.0) [computer software]. (Tokyo, Japan: Wased University. Available from http://www.laurenceanthony.net 2015).

Baker, Paul., Costas, Gabrielatos., Majid, Khosravinik., Michał, Krzyżanowski., Tony, McEnery. \& Wodak, Ruth. A useful methodological synergy? Combining critical discourse analysis and corpus linguistics to examine discourses of refugees and asylum seekers in the UK press. Discourse \& Society 19 no. 3 , (2008): 273-306.

Bakhtin, Mikhail. M. The dialogic imagination: four essays. (In M. Holquist, Ed.; \& C. Emerson \& M. Holquist, Trans. Austin: University of Texas Press. 1981).

Becher, Tony, and Paul Trowler. Academic tribes and territories ( $2^{\text {nd }}$ ed.). (Buckingham: The Open University Press 2001).

Becher, Tony. The significance of disciplinary differences. Studies in Higher Education 19 no. 2, (1994):151161. doi: 10.1080/03075079412331382007.

Biber, Douglas. \& Conrad, Susan. Register, genre, and style. (Cambridge: Cambridge University Press. 2009).

Biglan, Anthony. Relationships between subject matter characteristics and the structure and output of university departments. Journal of Applied Psychology 57 no. 3, (1973): 207-213. 
Blackwell, James. W. The text-compositional architecture of university lectures: an exploration of genre and periodicity in spoken academic discourse Unpublished Doctoral Dissertation). UK: The University of Birmingham. 2010).

Clerehan, Rosemary., Moore, Tim. \& Vance, Sheila. Collaborating in the transition to tertiary writing. ASCILITE, (2001): 125-132.

Crawford Camiciottoli, Belinda. The languages of business studies lectures. (Amsterdam: John Benjamins. 2007).

Fox, Gwyneth. A comparison of 'policespeak' and 'normalspeak': a preliminary study. In: J.M. Sinclair, M. Hoey and G. Fox (eds), Techniques of Description. Spoken and Written Discourse. A Festschrift for Malcolm Coulthard. (pp. 40-72). London \& New York: Routledge. 1992).

Goffman, Erving. The presentation of self in everyday life. (New York: Doubleday Anchor. 1981).

Gyekye, Kwame. The Akan concept of a person. In A. R. Wright (Ed.). African Philosophy: an introduction (pp. 101-122). Lanham, Md.: University Press of America. 1984).http://ucrel.lancs.ac.uk/llwizard. html. Accessed 9 July).

Hyland, Ken. Academic discourse: English in a global context. (London: Continuum. 2009).

Hyland, Ken. Authority and invisibility: authorial identity in academic writing. Journal of Pragmatics 34, (2002a):1091-1112.

Hyland, Ken. Disciplinary discourses: social interactions in academic writing. (London: Longman. 2000)

Hyland, Ken. Options of identity in academic writing. ELT Journal 56 no. 4, (2002b): 351-358.

Hyland, Ken. Stance and engagement: a model of interaction in academic discourse. Discourse Studies 7 no. 2, (2005): 173-192.

Jones, Stacy. H. The way we were, are and might be: torch singing as autoethnography. In A. P. Bochner \& C. Ellis (Eds.) Ethnographically speaking: Autoethnography, Literature, and Aesthetics (pp. 44-56).

Walnut Creek: AltaMira Press. 2002).

Kagan, Jerome. The three cultures: Natural sciences, social sciences, and the humanities in the 21 st century (Cambridge: Cambridge University Press. 2009).

Kamio, Akio. English generic we, you, and they: An analysis in terms of territory of information. Journal of Pragmatics 33, (2001): 1111-1124.

Koester, Almut. Building small specialised corpus. (In A. O'Keeffe, \& M McCarthy (Eds.). The Routledge handbook of corpus linguistics (pp. 66-79). London: Routledge. 2010).

Lee, Joseph. J. Size matters: an exploratory comparison of small and large class university lecture introductions. English for Specific Purposes 28 no. 1, (2009): 42-57.

literature review chapters. ESP World 57 no. 21, (2019):1-31.

MacDonald, Susan. P. Professional academic writing in the humanities and social sciences. (Carbondale:

Southern Illinois University Press. 1994).

McEnery, Tony. \& Hardie, Andrew. Corpus Linguistics: Method, theory and practice. (Cambridge: Cambridge University Press. 2012).

Meyer, Charles. F. English corpus linguistics: an introduction. Cambridge: Cambridge University Press. 2002).

O'keeffe, Anne., McCarthy, Michael. \& Carter, Ronald. From corpus to classroom. (Cambridge: Cambridge University Press. 2007).

Querol-Julián, Mercedes. The role of questions in English academic lectures. Newcastle Working Papers in Linguistics 14, (2008):100-111.

Rayson, Paul. (n.d.). Log-likelihood calculator [Computer Software]. (UK: Lancaster University.

Rounds, Patricia. L. Multifunctional personal pronouns use in educational setting. English for Specific Purposes 6 no 1, (1987): 13-29.

Scheibman, Joanne. Inclusive and exclusive patterning of the English first person plural: Evidence from conversation. Language, Culture and Mind, (2004): 377-396.

Simpson, Rita., Briggs, Sarah., Ovens, Janine., \& Swales, John. M. The Michigan corpus of academic spoken English. (Ann Arbor: The Regents of the University of Michigan. 2002). 
Sinclair, John. \& Carter, Roland. Trust the text: language, corpus and discourse. (New York: Routledge. 2004). Tuathail, Gearóid. Ó., \& Agnew, John. Geopolitics and discourse: practical geopolitical reasoning in American foreign policy. Political Geography 11 no. 2, (1992): 190-204.

Yaakob, Salmah Binti. A genre analysis and corpus-based study of university lecture introductions. Unpublished doctoral dissertation. (The University of Birmingham, UK 2013).

Yeo, Jiin-Yih, \& Su-Hie Ting. Personal pronouns for student engagement in arts and science lecture introductions. English for Specific Purposes 34, (2014): 26-37.

Zhihua, Guo. The use of personal pronouns in university lectures. (Paper presented at University of Applied Sciences Language Structure and Language Learning Conference. 2011) http://fl.hs.yzu.edu.tw/wlsll/ ppt/16.pdf 25/July/2015 